\title{
Change in Microstructure, Mechanical Strength and Corrosion Resistance of Ti-8Mo-xNi Alloys through Various Sintering Temperatures
}

\author{
Cheng Liang, ${ }^{1, *}$, Shih-Hsien Chang ${ }^{2}$, Wei-De Wang ${ }^{2}$, Kuo-Tsung Huang ${ }^{3}$ and Shun-Tian Lin ${ }^{1}$ \\ ${ }^{1}$ Department of Mechanical Engineering, National Taiwan University of Science and Technology, Taipei 10607, Taiwan, R. O. China \\ ${ }^{2}$ Department of Materials and Mineral Resources Engineering, National Taipei University of Technology, \\ Taipei 10608, Taiwan, R. O. China \\ ${ }^{3}$ Department of Auto-Mechanics, National Kangshan Agricultural Industrial Senior High School, Kaohsiung 82049, Taiwan, R. O. China
}

In this study, three different powders are mixed and used to produce Ti-8Mo-xNi alloys in three different proportions: Ti-8Mo-4Ni, Ti$8 \mathrm{Mo}-6 \mathrm{Ni}$ and Ti-8Mo-8Ni. The Ti-Mo-Ni alloys simultaneously undergo various vacuum sintering temperatures of $1125,1150,1175$ and $1200^{\circ} \mathrm{C}$, respectively. The experimental results show that the Ti-8Mo-8Ni alloys acquire a higher sintering density (98.9\%) and hardness (52.1 HRC) after sintering at $1175^{\circ} \mathrm{C}$ for $1 \mathrm{~h}$. However, due to the grain growth and increased amount of nickel in the Ti-8Mo-8Ni alloys, the transverse rupture strength (TRS) shows an obvious decrease (as compared with Ti-8Mo-6Ni, the TRS value decreasing from 1177 to $685 \mathrm{MPa}$ ). Consequently, the suitable Ni content of the Ti-8Mo-6Ni alloys which proves advantageous to the TRS results from the uniform distribution of the TiNi intermetallic compound precipitates within the $\beta$ matrix. The sintered Ti-8Mo-8Ni alloys also possess the lowest corrosion current $\left(\mathrm{I}_{\text {corr }}=1.87 \times 10^{-7} \mathrm{~A} \cdot \mathrm{cm}^{-2}\right)$ and highest polarization resistance $\left(56084 \Omega \cdot \mathrm{cm}^{2}\right)$ in $3.5 \mathrm{mass} \% \mathrm{NaCl}$ solutions. This result confirms that sintered Ti-8Mo-8Ni alloys effectively improve corrosion resistance. [doi:10.2320/matertrans.M2016044]

(Received February 2, 2016; Accepted June 3, 2016; Published July 25, 2016)

Keywords: titanium-molybdenum-nickel alloys, vacuum sintering, hardness and corrosion resistance

\section{Introduction}

The superior physical phenomena of titanium alloys are that it is lightweight, has strong mechanical properties and, most particularly, it has a low elastic modulus and low density, which gives it a low thermal conductive coefficient $\left(17 \mathrm{~W} \cdot \mathrm{m}^{-1} \cdot \mathrm{K}^{-1}\right)$ as compared with conventional metals. The chemical properties of titanium alloys include good resistance to corrosion, good antiseptic properties and high biocompatibility with humans. These properties make titanium alloys the most common choice for biomaterial implants in human bodies. ${ }^{1,2)}$

During the past few decades, $\beta$ titanium alloys have become one of the most promising candidates due to their high specific strength and good corrosion resistance. In the as-solution treated condition, the tensile properties of $\beta$ titanium alloys have been reported to depend significantly on the deformation mode, which is closely associated with the $\beta$ phase stability. ${ }^{3-5)}$ Mo is desirable as an alloying element for the development of Ti-based biomaterials. Previous research have studied the phase transformations and mechanical properties of different Ti-Mo alloys, and found that the phase constitutions, elastic modulus and hardness are different for TiMo alloys with different Mo contents. ${ }^{6,7)}$ Until now, a lot of investigation on binary Ti-Mo alloys has been developed with concentration on microstructure, mechanical properties and electrochemical behavior. It is remarkable that the Ti-8Mo exhibits the highest mechanical properties among the porous Ti-(4-10 mass\%)Mo alloys. ${ }^{8)}$

Powder metallurgy $(\mathrm{P} / \mathrm{M})$ methods offer varied types of materials with the objective of achieving higher strength, hardness and wear resistance for composite materials such as Cobalt-based alloys and Titanium-based alloys powders. ${ }^{7)}$ Conventional $\mathrm{P} / \mathrm{M}$ involves mixing the metal powders, com-

*Corresponding author, E-mail: lcheng@ntut.edu.tw pacting of the mixed powders into molds and then sintering of the compact powders under the different atmospheres. ${ }^{9,10)}$ One of the advantages of $\mathrm{P} / \mathrm{M}$ compared to other methods is having better control on the microstructure, where better distribution of the reinforcements is possible in $\mathrm{P} / \mathrm{M}$ compacts. ${ }^{11)}$ However, sintered $\mathrm{P} / \mathrm{M}$ parts usually over $5 \%$ porosity. Enhanced sintering techniques can be applied to obtain higher density and reduced porosity in sintered parts. Liquidphase sintering (LPS) is well recognized as a convenient process route for achieving near-full theoretical sintered densities for many $\mathrm{P} / \mathrm{M}$ martensite alloys. ${ }^{12)}$ The purpose of this work was to demonstrate the feasibility achieving near-full theoretical density of P/M Ti alloys via LPS.

Previous study indicated that when the Ti alloys contain 8 at $\%$ Mo or more, $\beta$ phase become the only dominant phase. It is well known that $\omega$ phase is formed in the metastable $\beta$ type alloys, and the amount of $\omega$ phase depends significantly on the stability of the $\beta$ phase. With the increase of Mo content $(8 \%)$, the $\beta$ phase is more stable. Thus, the formation of $\omega$ phase during cooling is suppressed in high $\beta$ stable Ti-Mo alloy. ${ }^{6,8)}$ Zhao et al. also found that $\omega$ phase is formed in the metastable $\beta$ type alloys with different Mo contents and disappeared in Ti-Mo alloys with high Mo content. ${ }^{13)}$ Ti-Mo alloys are not always the most suitable for the particular purpose. This factor is also the reason for seeking optimized variants of these original binary systems. One of the possible solutions is to modify binary alloys by incorporation of one or more chemical elements into the production process. Ti-Ni based alloys have quite good properties such as corrosion resistance and abrasion resistance. Although Ti-Ni is a kind of intermetallic compound, it is quite ductile, under certain conditions $60 \%$ cold working being possible. ${ }^{14)}$ Thus Ti-Mo alloy added with different amounts of Ni powders as a strengthening phase to obtain better mechanical properties still needs to be further investigated. Our previous study has shown that the combination of these elements in a Ti-Mo-Ni alloy has a 
good balance between mechanical properties and hot workability (excellent sintering ability due to the immersion of a temporary liquid phase at the start of the sintering process). However we have succeeded in developing a new high performance $\beta$-titanium alloy composite using vacuum sintering process.

The present research selected the Ti and Mo alloy powders based on the high $\beta$ stability of Ti-8Mo alloys; the different amounts of nickel were added as a strengthening element. The effects of the microstructural evolution on the mechanical properties and corrosion resistance of Ti-8Mo-xNi alloys through the vacuum sintering process at various temperatures were determined.

\section{Experimental Procedure}

In this research, different amounts of refined nickel powder (4, 6 and 8 mass $\%$ ) were added to Ti and Mo alloy powders. The Ti (92-x)\%-Mo 8\% alloys had $\mathrm{x}$ amount of refined nickel powder added; therefore, the Ti-8Mo powder samples with the various added amounts of refined nickel powder were denoted as Ti-8Mo-4Ni, Ti-8Mo-6Ni and Ti-8Mo-8Ni, respectively. In this study, the PVA (polyvinyl alcohol) as a binder was added. The green body $\left(40 \times 6 \times 8 \mathrm{~mm}^{3}\right)$ of the powder specimen was produced under a uniaxial pressure at $40 \mathrm{MPa}$ for $300 \mathrm{sec}$. The vacuum sintering was conducted at 1125 , 1150,1175 , and $1200^{\circ} \mathrm{C}$ for $1 \mathrm{~h}$ in a $1.3 \times 10^{-3} \mathrm{~Pa}$, respectively. Previous study indicated that the impurity concentrations of vacuum-sintered commercially pure titanium with fine grains were sufficiently low to meet the ASTM standard. It illustrates that the oxygen, nitrogen and hydrogen contents of the specimens was lower than that of ASTM (B381-10). ${ }^{15)}$ As a result, the contamination levels such as oxygen, nitrogen and hydrogen can be ignored. In this study, the XRD patterns also confirm that there are no other oxide appeared in the specimens (Fig. 1). A Microtrac X 100 laser was used to analyze the particle size of the refined $\mathrm{Ti}$, Mo and Ni powders. The mean particle sizes of the reduced Ti, Mo and Ni powders were about $28.4 \pm 0.3,12.4 \pm 0.5$ and $9.9 \pm 0.7 \mu \mathrm{m}$, respectively. Moreover, the morphology of $\mathrm{Ti}$ and $\mathrm{Ni}$ reduced powders show an irregularly shaped surface (polygon), as shown in Figs. 2(a) and 2(b). However, the morphology of Mo revealed an acicular crystal, which combined Mo with oxygen to form the $\mathrm{MoO}_{3}$, as shown in Fig. 2(c).

To evaluate the effects of microstructure evolution on the Ti-8Mo-xNi alloys via vacuum sintering process, this study conducted volume shrinkage rate, relative density, hardness, Transverse Rupture Strength (TRS) tests, Optical Microscopy $(\mathrm{OM})$ and Scanning Electron Microscopy (SEM) microstructure observations. The Hung Ta universal material test machine (HT-9501A) with a maximum load of $245 \mathrm{kN}$ was used for the transverse rupture strength (TRS) tests (ASTM B528-05). Meanwhile, $\mathrm{R}_{\mathrm{bm}}$ was the TRS, which is determined as the fracture stress in the surface zone. F was maximum fracture load, L was $30 \mathrm{~mm}$, $\mathrm{k}$ was chamfer correction factor (normally $1.00-1.02$ ), $\mathrm{b}$ and h were $5 \mathrm{~mm}$ in the equation $\mathrm{R}_{\mathrm{bm}}=3 F L k / 2 b h^{2}$, respectively. The specimen dimensions of the TRS test were $5 \times 5 \times 40 \mathrm{~mm}^{3}$. Porosity test was conducted in accordance to the ASTM C373-88 standard. Hardness tests were measured by HRC with a loading of

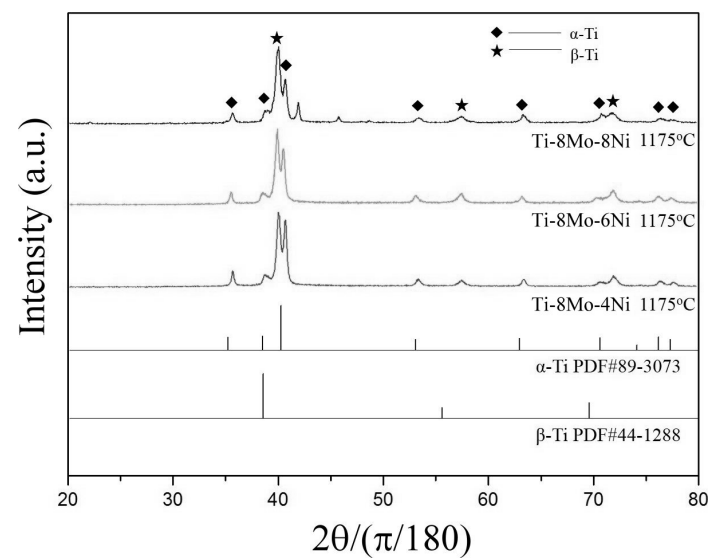

Fig. 1 XRD patterns of the Ti-8Mo-xNi after sintering at $1175^{\circ} \mathrm{C}$ for $1 \mathrm{~h}$.
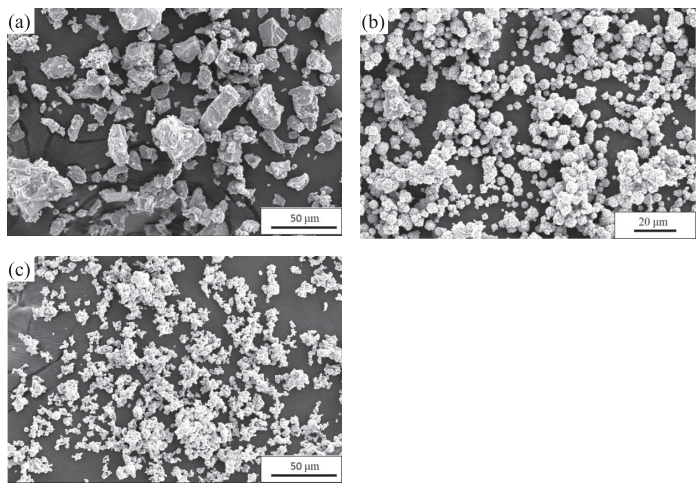

Fig. 2 SEM photographs of the surface morphology of different refined powders: (a) titanium (b) nickel, and (c) molybdenum powders, respectively.

$1.47 \mathrm{kN}$, which followed the ASTM E18-3 standard.

Furthermore, corrosion potential analysis uses three electrodes method and follows by ASTM G59-97: the reference electrode is a saturated of silver-silver chloride electrode, auxiliary electrode uses a platinum electrode, and the working electrode is connected to the test specimens. ${ }^{16)}$ The contact area of the specimen was $0.785 \mathrm{~cm}^{2}$. The corrosive solvent used 3.5 mass $\% \mathrm{NaCl}$ was maintained at room temperature. A scanning speed of $0.01 \mathrm{Vs}^{-1}$, initial potential of $-2.0 \mathrm{~V}$, and the final potential of $2.0 \mathrm{~V}$ were controlled. The polarization curve was obtained by Corr-View software to analyze and compare the corrosion potential $\left(\mathrm{E}_{\mathrm{corr}}\right)$, corrosion current $\left(\mathrm{I}_{\text {corr }}\right)$ and polarization resistance $\left(\mathrm{R}_{\mathrm{p}}\right)$ of Ti-8Mo-xNi sintered specimens.

\section{Results and Discussion}

\subsection{Effect of Ni content and sintering temperature on microstructure}

Table 1 lists the volume shrinkage rate of the Ti-8Mo-xNi alloys resulting from the different sintering temperatures. The volume shrinkage rate of the Ti-8Mo-xNi specimens significantly increased as the added amount of Ni increased. Moreover, increasing the sintering temperature also improved the volume shrinkage rate. As a result, the Ti-8Mo-8Ni possessed a higher volume shrinkage rate after sintering at $1175^{\circ} \mathrm{C}$ and 
Table 1 Comparison of the relative density and shrinkage of Ti-8Mo-xNi alloys after various sintering temperatures.

\begin{tabular}{cccc}
\hline $\begin{array}{c}\text { Sintering } \\
\text { Temperatures }\left({ }^{\circ} \mathrm{C}\right)\end{array}$ & Specimens & $\begin{array}{c}\text { Volume } \\
\text { shrinkage }(\%)\end{array}$ & $\begin{array}{c}\text { Relative } \\
\text { density }(\%)\end{array}$ \\
\hline \multirow{3}{*}{1125} & Ti-8Mo-4Ni & $28.4 \pm 0.3$ & $92.7 \pm 0.2$ \\
& Ti-8Mo-6Ni & $29.0 \pm 0.1$ & $93.5 \pm 0.3$ \\
& Ti-8Mo-8Ni & $29.4 \pm 0.1$ & $95.0 \pm 0.7$ \\
\hline \multirow{3}{*}{1150} & Ti-8Mo-4Ni & $29.0 \pm 0.7$ & $93.6 \pm 0.1$ \\
& Ti-8Mo-6Ni & $29.5 \pm 0.7$ & $94.7 \pm 0.1$ \\
& Ti-8Mo-8Ni & $30.9 \pm 0.3$ & $98.9 \pm 0.2$ \\
\hline \multirow{3}{*}{1175} & Ti-8Mo-4Ni & $28.5 \pm 0.2$ & $94.0 \pm 0.1$ \\
& Ti-8Mo-6Ni & $30.1 \pm 0.3$ & $94.9 \pm 0.2$ \\
& Ti-8Mo-8Ni & $32.7 \pm 0.8$ & $98.9 \pm 0.5$ \\
\hline \multirow{2}{*}{1200} & Ti-8Mo-4Ni & $30.9 \pm 0.5$ & $95.4 \pm 0.1$ \\
& Ti-8Mo-6Ni & $31.2 \pm 0.5$ & $96.3 \pm 0.1$ \\
& Ti-8Mo-8Ni & $32.8 \pm 0.7$ & $97.3 \pm 1.6$ \\
\hline
\end{tabular}
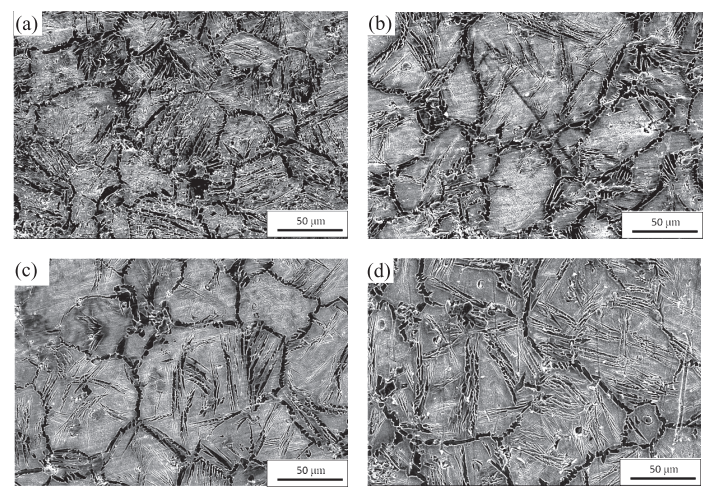

Fig. 3 Comparison of SEM morphology observations of Ti-8Mo-4Ni alloys by vacuum sintering at different temperatures (a) $1125^{\circ} \mathrm{C}$, (b) $1150^{\circ} \mathrm{C}$, (c) $1175^{\circ} \mathrm{C}$, and (d) $1200^{\circ} \mathrm{C}$.

$1200^{\circ} \mathrm{C}$ for $1 \mathrm{~h}$. It is reasonable to suggest that the Ti-Mo-Ni alloys effectively filled the voids during the sintering process, which led to the small pores in the specimens decreasing, since the higher temperature sintering enhanced the volume shrinkage rate. Table 1 also shows that the relative density of the Ti-8Mo-xNi specimens obviously increased as the added amount of $\mathrm{Ni}$ increased and that the relative density improved as the sintering temperatures increased. These results when further compared with the SEM images of the Ti-8Mo-xNi specimens in Figs. 3, 5 and 6 showed that the pores decreased as the added amount of $\mathrm{Ni}$ increased. The specimens with higher $\mathrm{Ni}$ contents required lower temperatures to provide sufficient sintering energy for a complete LPS. Thus, the Ti$8 \mathrm{Mo}-8 \mathrm{Ni}$ specimens had a higher relative density after sintering at $1150^{\circ} \mathrm{C}$ and $1175^{\circ} \mathrm{C}$ for $1 \mathrm{~h}$. The higher amount of $\mathrm{Ni}$ $(8 \%)$ in the $\mathrm{Ti}-8 \mathrm{Mo}-8 \mathrm{Ni}$ specimens advantageous to the relative density resulted from the increase in the diffusion rate at relatively low sintering temperatures. Previous research indicated that the activation energies of Ti-Ni alloys decreased as the nickel content increased, and that the liquid phase's TiNi intermetallic compounds formed in the grain boundaries during the sintering process. These compounds have a highly reactive and exothermic effect which results in an increase in the volume shrinkage rate. ${ }^{17)}$ It was reasonable to speculate that the TiNi intermetallic compounds significantly affected the relative density. Through increasing the added amount of
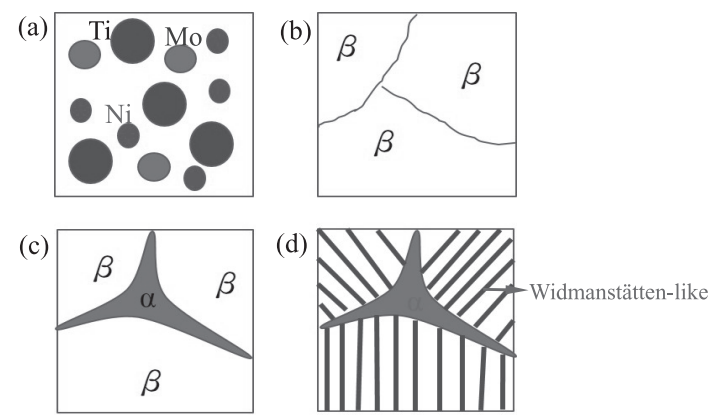

Fig. 4 Schematic illustration of Widmanstätten-like structures.
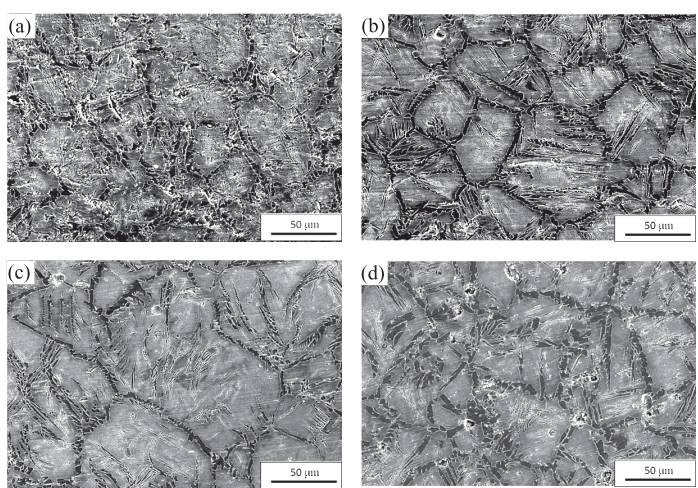

Fig. 5 Comparison of SEM morphology observations of Ti-8Mo-6Ni alloys by vacuum sintering at different temperatures (a) $1125^{\circ} \mathrm{C}$, (b) $1150^{\circ} \mathrm{C}$ (c) $1175^{\circ} \mathrm{C}$, and (d) $1200^{\circ} \mathrm{C}$.

$\mathrm{Ni}(8 \%)$ and the sintering temperature $\left(1175^{\circ} \mathrm{C}\right)$, the near-full density of the Ti-8Mo-8Ni alloy could be acquired.

Figure 3 shows that SEM morphology observations of the microstructure of the Ti-8Mo-4Ni alloys vacuum sintered at different temperatures. The porosity significantly decreased as the sintering temperature increased. Also, the acicular precipitates in the matrix and the grain size tended to increase as the sintering temperature increased. However, the acicular precipitates obviously displayed a coarse phenomenon after sintering at $1200^{\circ} \mathrm{C}$ for $1 \mathrm{~h}$, which affected the mechanical properties. A diffusional transformation structure (Widmanstätten-like structure) formed when the $\alpha+\beta$ titanium alloys were rapidly cooled from the $\beta$ region; while the Widmanstätten-like structure of the Ti-Mo-xNi alloys developed as illustrated in Fig. 4. Figure 4(a) and 4(b) show that the microstructures of the Ti-8Mo-xNi specimens were sintered at $1125-1200^{\circ} \mathrm{C}$ for $1 \mathrm{~h}$. In titanium alloy, grain growth was generally fast in the $\beta$ region, and the microstructure of the specimens rapidly cooled from $1125-1200^{\circ} \mathrm{C}$ in the $\beta$ region to room temperature; the $\alpha$ phase was preferentially precipitated plate-like at the grain boundaries of the $\beta$ matrix under the different sintering temperatures where the diffusional transformation was fully possible (Fig. 4(c)). As the cooling time extended, the side-plate $\alpha$ phase formed and then the side-plates formed in aggregates within the $\beta$ matrix (Fig. 4(d)), forming the so-called Widmanstätten-like structure. ${ }^{18)}$

Figure 5 shows the SEM morphology observations of the Ti-8Mo-6Ni alloys vacuum sintered at different temperatures. The acicular precipitates within the $\beta$ matrix (Widmanstät- 

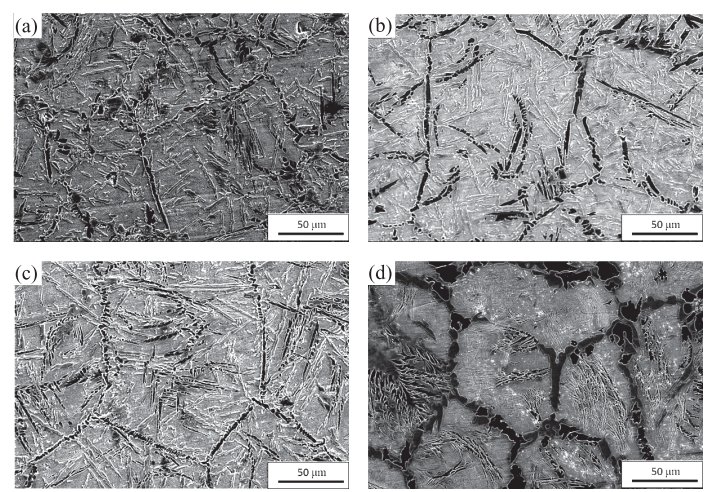

Fig. 6 Comparison of SEM morphology observations of Ti-8Mo-8Ni alloys by vacuum sintering at different temperatures (a) $1125^{\circ} \mathrm{C}$, (b) $1150^{\circ} \mathrm{C}$, (c) $1175^{\circ} \mathrm{C}$, and (d) $1200^{\circ} \mathrm{C}$

ten-like structure) and the grain size increased as the sintering temperature increased to $1175^{\circ} \mathrm{C}$. However, when the sintering temperature increased to $1200^{\circ} \mathrm{C}$, the $\alpha$ phase (darker region) in the grain boundaries grew, and it nucleated and grew within the $\beta$ matrix. Moreover, the acicular precipitates were not uniformly distributed within the $\beta$ matrix. When compared with Fig. 3, it can be seen that the porosity decreased slightly as the added amount of Ni increased. Figure 6 shows the SEM morphology observations of the Ti-8Mo-8Ni alloys vacuum sintered at different temperatures. The acicular precipitates within the $\beta$ matrix coarsened when the sintering temperature increased to $1175^{\circ} \mathrm{C}$. When the sintering temperature increased to $1200^{\circ} \mathrm{C}$, the highest temperature for the sintering process, the partial melting phenomenon appeared on the Ti-8Mo-8Ni specimens. Figure 6(d) showed that the acicular precipitates were not uniformly distributed within the $\beta$ matrix due to the excessive precipitates, and the grains combined together to grow up. A comparison with Figs. 3 and 5 shows that the acicular precipitates within the $\beta$ matrix became coarser as the added amount of $\mathrm{Ni}$ increased. It was possible to say that the acicular precipitates were enhanced as the Ni content of the Ti-8Mo-xNi specimens increased as a result of the decrease in the liquid-phase sintering (LPS) temperature.

The compositions and amounts of the elements of the Ti$8 \mathrm{Mo}-\mathrm{xNi}$ alloys were determined. As the high magnification of the Ti-8Mo-6Ni image in Fig. 7(a) shows, plate-like (black) titanium surrounded the grains and the threadlike precipitates (white) were randomly dispersed within the grains. Figures 7(b)-(d) show the EDS analysis of the Ti-8Mo-6Ni specimen. The location of the (1), (2) and (3) regions revealed the plate-like (black) regions to be $\alpha$ titanium, the threadlike precipitates (white) TiNi intermetallic compounds and the gray color as Mo-rich $\beta$ titanium, respectively. These results confirmed that the oversaturated $\mathrm{Ni}$ which precipitated as TiNi intermetallic compounds coexisted with $\beta$ titanium; moreover, the $\alpha$ titanium precipitated plate-like at the grain boundaries of the $\beta$ matrix. The Ti-Mo-Ni materials formed $\alpha+\beta$ titanium alloys. The results agree with the XRD finding (Fig. 1).
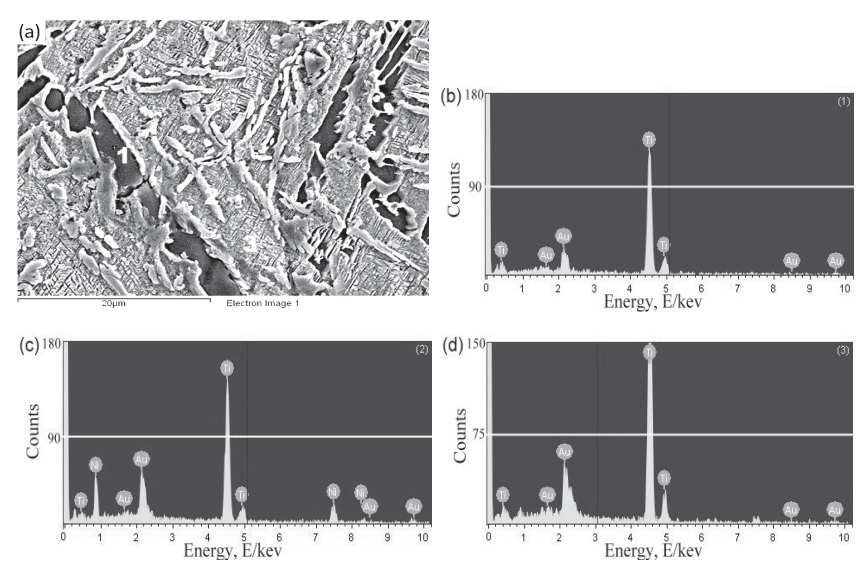

Fig. 7 EDS analysis of Ti-8Mo-6Ni alloys by vacuum sintering at $1175^{\circ} \mathrm{C}$ (a) a high magnified SEM image, (b) location 1, (c) location 2, and (d) location 3.

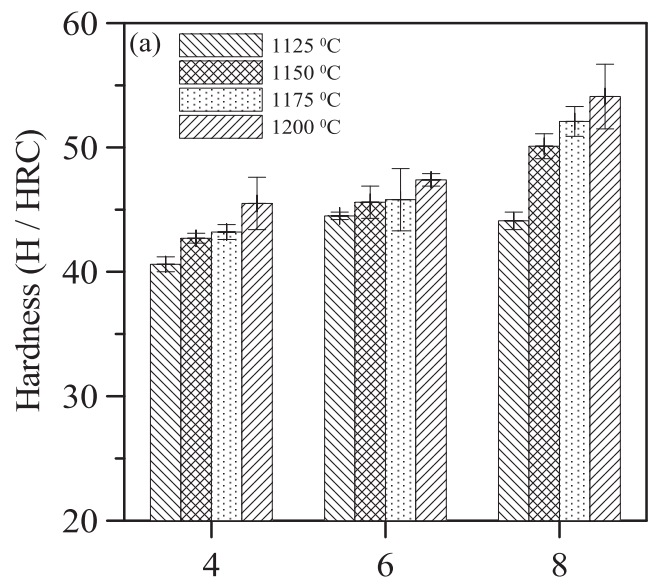

The different addition of $\mathrm{Ni}(\mathrm{M} / \operatorname{mass} \%)$

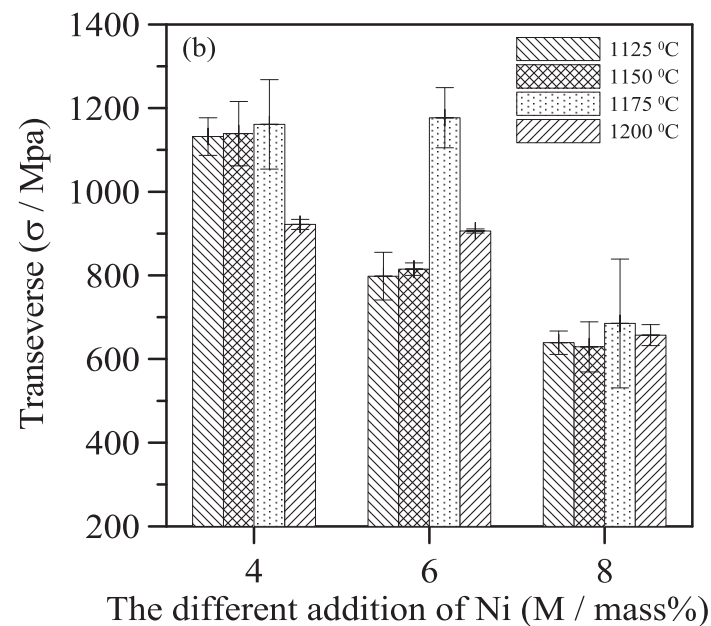

Fig. 8 Comparison of the mechanical properties of Ti-8Mo-xNi alloys by vacuum sintering at different temperatures (a) hardness, and (b) TRS test result.

\subsection{Effect of Ni content and sintering temperature on mechanical properties}

Figure 8(a) shows the hardness test results of the Ti-8Mo$\mathrm{xNi}$ specimens after sintering at different temperatures. The hardness of the Ti-8Mo-xNi specimens improved as the sintering temperature increased, and it was dramatically improved as the added amount of $\mathrm{Ni}$ increased. The literature 
indicates that decreasing the porosities and increasing the density of sintered materials effectively enhances plastic deformation resistance and hardness. ${ }^{10,19)}$ The results can be further compared with Figs. 3, 5, 6 and Fig. 8(a). The porosities decreased and the relative density increased as the sintering temperature was raised, which could be the main factor in improving hardness. Besides, the TiNi intermetallic compounds belong to the hard and brittle materials uniformly distributed in the $\beta$ matrix, which could be another factor in improving the hardness. Previous study indicated that the microhardness of TiNi compounds measured by the Vickers indenter was about $773.6 \pm 123 \mathrm{HV}_{0.05}{ }^{20)}$ As a result, the higher hardness appeared in the Ti-8Mo- $8 \mathrm{Ni}$ specimens, and the highest hardness value of HRC 54.1 appeared after sintering at $1200^{\circ} \mathrm{C}$ for $1 \mathrm{~h}$. This could be ascribed to the higher relative density and dispersion-strengthened TiNi compounds. Figure 8(b) shows the TRS values of the Ti-8Mo-xNi specimens after sintering at various temperatures, with the values slightly increasing as the sintering temperature increased to $1175^{\circ} \mathrm{C}$. However, the TRS values of the Ti-8Mo-xNi specimens significantly decreased as the added amount of $\mathrm{Ni}$ increased, and when the added amount of $\mathrm{Ni}$ increased to $8 \%$, the TRS value obviously decreased. The Ti-8Mo-8Ni specimens possessed the lowest TRS values, with the highest TRS value of $1177 \pm$ $72 \mathrm{MPa}$ appearing in the Ti-8Mo-6Ni specimens after sintering at $1175^{\circ} \mathrm{C}$ for $1 \mathrm{~h}$. Previous study has indicated that the needle-like microstructure of the Widmanstätten-like structure leads to brittle behavior of the carbon steels. However, it is good for the ductility of the Ti alloys. ${ }^{18)}$ From a comparison of the SEM observations (Figs. 3, 5 and 6) and TRS results (Fig. 8(b)), it is reasonable to suggest that the more Widmanstätten-like structure uniformly distributed in the Ti-8Mo-6Ni specimens after sintering at $1175^{\circ} \mathrm{C}$ for $1 \mathrm{~h}$. As a result, the amount of Widmanstätten-like structure increase is effective in improving the TRS values.

On the other hand, the excessive precipitation of TiNi intermetallic compounds within the $\beta$ matrix and the grain coarsening (grain growth and combination) appeared as the added amount of $\mathrm{Ni}$ increased, which were disadvantageous to the TRS. The results were further compared with the fracture surfaces of the Ti-8Mo-xNi specimens, and it was determined that specimens with the same amount of added $\mathrm{Ni}$ and which underwent the different sintering temperatures showed similar fracture features. Taking the Ti-8Mo-xNi specimens sintered at $1175^{\circ} \mathrm{C}$ as an example, the pores, small cleavages and dimple features could be clearly observed as the added amount of Ni increased to 6\%, as shown in Figs. 9(a) and (b). It is possible to say that a greater number of dislocations were generated by the plastic extension when the fracture was under continually increasing loads. If the precipitates can resist the movement of dislocation, then the strength is improved. ${ }^{21)}$ As the load increases, micro-voids gradually grow and coalesce and eventually fracture. This mode of fracture is called dimple rupture. ${ }^{22)}$ The TiNi intermetallic compounds belong to brittle materials, and the excessive precipitates affect the fracture feature. When the added amount of $\mathrm{Ni}$ increased, the acicular TiNi intermetallic compound precipitates increased within the $\beta$ matrix. By increasing the added amount of $\mathrm{Ni}$ to $8 \%$, the fracture feature presented bigger cleavages and brittle features resulted from excessive precipitation of TiNi inter-

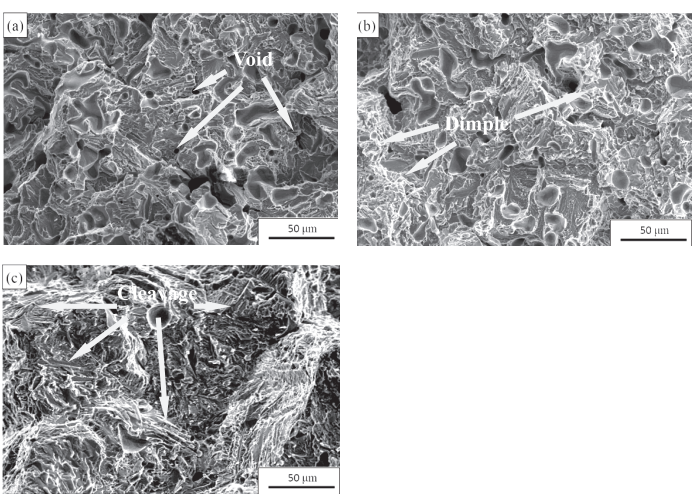

Fig. 9 Fractographs observation of Ti-8Mo-xNi alloys after added different amounts of $\mathrm{Ni}$ by vacuum sintering at $1175^{\circ} \mathrm{C}$ for $1 \mathrm{~h}$ (a) $4 \%$, (b) $6 \%$, and (c) $8 \%$

metallic compounds and grain coarsening, and the main fracture mode failed in the transgranular cleavage. The rupture feature compared with Fig. 9(b), shows a suitable amount of TiNi intermetallic compound precipitates to be uniformly distributed within the $\beta$ matrix, thereby increasing the TRS of the Ti-8Mo-xNi materials. However, an excessive precipitation of brittle TiNi intermetallic compounds within the $\beta$ matrix that resulted in the brittle rupture, as shown in Fig. 9(c). It was detrimental to the TRS value and explains why the Ti$8 \mathrm{Mo}-8 \mathrm{Ni}$ specimens possessed the lowest TRS value. The fracture surface observations were in agreement with the SEM findings and so provided verification that the acicular TiNi intermetallic compounds within the $\beta$ matrix played an important role in affecting the TRS value.

Figure 8(b) also shows that the TRS slightly increased as the sintering temperature increased to $1175^{\circ} \mathrm{C}$, and that the TRS obviously decreased as the sintering temperature increased to $1200^{\circ} \mathrm{C}$. The higher density provided stronger binding to protect the rupture mechanism of generation. Increasing the sintering temperatures effectively decrease the pores (improve the relative density, as shown in Table 1), which easily generated the points of stress concentration and formed a continuous rupture. However, when the sintering temperature increased to $1200^{\circ} \mathrm{C}$, the grains showed significant coarsening and combination (Figs. 3, 5 and 6), which was disadvantageous to the TRS. According to the above discussion and results, it was speculated that the Ti-8Mo- $6 \mathrm{Ni}$ specimens sintered at $1175^{\circ} \mathrm{C}$ for $1 \mathrm{~h}$ possessed the better mechanical properties.

\subsection{Effect of the Ni content and sintering temperature on corrosion resistance}

Table 2 lists the corrosion results of the Ti-8Mo-xNi specimens sintered at the different temperatures after a 3.5 mass $\%$ $\mathrm{NaCl}$ corrosion test. Previous study has indicated that Ti-Mo alloys exhibit a passive behavior in $5 \% \mathrm{HCl}$ solution, which is attributed to the passive film formation of a mixture of $\mathrm{MoO}_{3}$ and $\mathrm{TiO}_{2}{ }^{23)}$ Moreover, literature also indicated that Ti-Mo alloys exhibit a passive behavior in simulated body fluid solution, the corrosion resistance of the Ti-Mo alloys increased as the Mo content increased. Based on the results obtained from the polarization curve, the Ti-Mo alloys were shown to be corrosion resistant because of the passive films formed on 
Table 2 Comparison of the corrosion resistance of Ti-8Mo-xNi alloys by various sintering temperatures after 3.5 mass $\% \mathrm{NaCl}$ corrosion test.

\begin{tabular}{ccccc}
\hline $\begin{array}{c}\text { Sintering } \\
\text { Temperatures }\left({ }^{\circ} \mathrm{C}\right)\end{array}$ & Specimens & $\mathrm{I}_{\text {corr }}\left(\mathrm{A} \cdot \mathrm{cm}^{-2}\right)$ & $\mathrm{E}_{\text {corr }}($ Volts $)$ & $\mathrm{R}_{\mathrm{p}}\left(\Omega \cdot \mathrm{cm}^{2}\right)$ \\
\hline \multirow{3}{*}{1125} & Ti-8Mo-4Ni & $9.49 \times 10^{-7}$ & -1.03 & 36476 \\
& Ti-8Mo-6Ni & $2.24 \times 10^{-6}$ & -0.958 & 28456 \\
& Ti-8Mo-8Ni & $2.38 \times 10^{-6}$ & -1.02 & 26442 \\
\hline \multirow{3}{*}{1150} & Ti-8Mo-4Ni & $9.35 \times 10^{-7}$ & -0.899 & 30777 \\
& Ti-8Mo-6Ni & $7.91 \times 10^{-7}$ & -0.901 & 28570 \\
& Ti-8Mo-8Ni & $4.79 \times 10^{-7}$ & -0.903 & 36309 \\
\hline \multirow{3}{*}{1175} & Ti-8Mo-4Ni & $8.39 \times 10^{-7}$ & -1.158 & 30811 \\
& Ti-8Mo-6Ni & $4.37 \times 10^{-7}$ & -0.843 & 30751 \\
& Ti-8Mo-8Ni & $1.81 \times 10^{-7}$ & -0.870 & 56084 \\
\hline \multirow{2}{*}{1200} & Ti-8Mo-4Ni & $2.52 \times 10^{-7}$ & -1.008 & 32288 \\
& Ti-8Mo-6Ni & $9.62 \times 10^{-7}$ & -0.972 & 27461 \\
& Ti-8Mo-8Ni & $2.50 \times 10^{-6}$ & -0.965 & 27914 \\
\hline
\end{tabular}

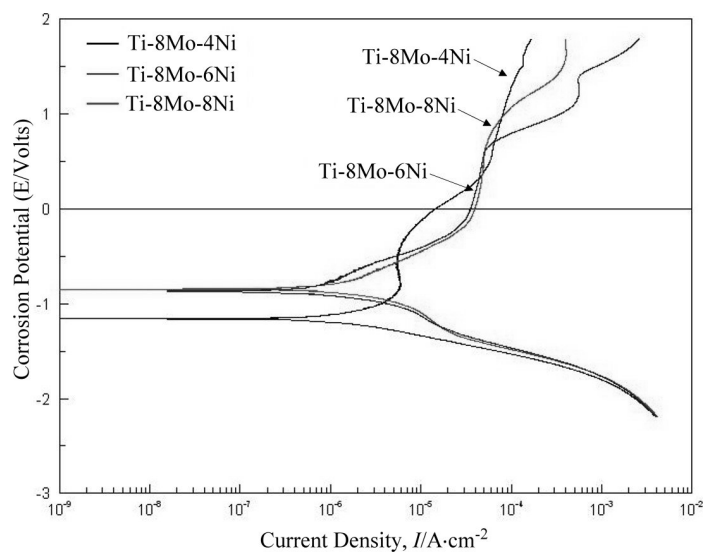

Fig. 10 Tafel results of Ti-8Mo-xNi specimens by vacuum sintering at $1175^{\circ} \mathrm{C}$ for $1 \mathrm{~h}$ after 3.5 mass $\% \mathrm{NaCl}$ corrosion test.

their surfaces. ${ }^{24)}$ In this work, all specimens formed a passive film on the surface, which is reasonable to suggest that normally results from the Mo-rich $\beta$ matrix. In an electrochemical reaction, the current value normally represents the diversification of the equilibrium constants in the oxidation reaction: a higher current value leads to an increase in the equilibrium constant and a fast oxidation rate. However, the polarization resistance must also be considered, as higher polarization resistance usually means better corrosion resistance. ${ }^{25,26)}$

Our previous study showed that the passivation probability in $-0.4 \sim-1.0 \mathrm{~V}$ crosses a potentially large range. ${ }^{27)}$ In this study, there was a slight change in the corrosion potential of the Ti-8Mo-xNi specimens, and the corrosion current varied through the different sintering temperatures and $\mathrm{Ni}$ contents after the corrosion tests. A lower corrosion current appeared at the $1175^{\circ} \mathrm{C}$ sintering temperature. Moreover, the corrosion current in the specimens sintered at $1175^{\circ} \mathrm{C}$ tended to decrease as the added amount of $\mathrm{Ni}$ increased, Ti-8Mo- $8 \mathrm{Ni}$ and Ti-8Mo-6Ni especially. The Ti-8Mo-8Ni and Ti-8Mo-6Ni specimens sintered at $1175^{\circ} \mathrm{C}$ for $1 \mathrm{~h}$ possessed the lower corrosion current. Differences in the corrosion current are closely related to the corrosion rate; therefore, a lower corrosion current leads to a lower corrosion rate. Significantly, the Ti$8 \mathrm{Mo}-8 \mathrm{Ni}$ specimens possessed the highest corrosion resistance. Figure 10 shows the Tafel results of Ti-8Mo-xNi spec- imens by vacuum sintering at $1175^{\circ} \mathrm{C}$ for $1 \mathrm{~h}$ after 3.5 mass $\%$ $\mathrm{NaCl}$ corrosion test. All the Ti-8Mo-xNi sintered alloys possessed a significant passivation phenomenon after the 3.5 mass \% NaCl corrosion test. On the whole, all the anodic polarization branches exhibit a similar behavior, gradually changing into passive state from Tafel region, a representative self-passivation feature. In addition, a porous material is often attacked not only on its surface but also from inside. Simultaneously, a more porous structure always suffers more corrosion than a less porous one. ${ }^{23)}$ In this study, the lowest $\mathrm{I}_{\text {corr }}\left(1.87 \times 10^{-7} \mathrm{~A} \cdot \mathrm{cm}^{-2}\right)$ and highest $\mathrm{R}_{\mathrm{p}}\left(56084 \Omega \cdot \mathrm{cm}^{2}\right)$ appeared in the Ti-8Mo-8Ni specimens after sintering at $1175^{\circ} \mathrm{C}$ for $1 \mathrm{~h}$, which effectively improved the corrosion resistance. The result can be further compared with the relative density as listed in Table 1, the relative density of Ti-8Mo-XNi specimens after sintering at $1175^{\circ} \mathrm{C}$ for $1 \mathrm{~h}$ increases as the added amount of $\mathrm{Ni}$ increased. It is reasonable to suggest that the electrochemical characteristics are principally controlled by porous features. Potentiodynamic polarization results reveal that $I_{\text {corr }}$ values increase with the increase of porosity, indicating a reduced corrosion resistance. According to the above discussion and results, it was speculated that the Ti-8Mo-6Ni specimens sintered at $1175^{\circ} \mathrm{C}$ for $1 \mathrm{~h}$ possessed the optimal TRS (bending strength) and better corrosion resistance, which result from the more amount and uniform distribution of Widmanstätten-like structure and higher relative density.

\section{Conclusions}

In this study, we investigated the microstructure, mechanical properties and corrosion resistance of Ti-8Mo-xNi alloys after sintering at different temperatures. The conclusions of this study are summarized as follows:

(1) Significant Widmanstätten-like structures formed on the $\beta$ titanium matrix of the Ti-8Mo-xNi alloy specimens. Furthermore, the acicular TiNi intermetallic compound precipitates within the Widmanstätten-like structure increased as the added amount of $\mathrm{Ni}$ increased.

(2) A higher sintering density (98.9\%) and hardness (52.1 HRC) of the Ti-8Mo-8Ni alloys were acquired after sintering at $1175^{\circ} \mathrm{C}$ for $1 \mathrm{~h}$. However, the TRS value $(685 \mathrm{MPa})$ showed an obvious decrease. Besides, the Ti$8 \mathrm{Mo}-6 \mathrm{Ni}$ alloys possessed a relatively high relative density $(94.9 \%)$ and hardness (42.8 HRC), but the highest TRS value of $1177 \mathrm{MPa}$ was reached after sintering at $1175^{\circ} \mathrm{C}$ for $1 \mathrm{~h}$. Consequently, the suitably and uniformly distributed TiNi intermetallic compounds within the $\beta$ matrix were advantageous to the TRS.

(3) All Ti-8Mo-xNi specimens formed a passive film, which contributed to better anti-corrosion properties during the corrosion tests. The lowest $\mathrm{I}_{\text {corr }}$ and highest $\mathrm{R}_{\mathrm{p}}$ appeared in the Ti-8Mo-8Ni specimens after sintering at $1175^{\circ} \mathrm{C}$ for $1 \mathrm{~h}$, which effectively improved the corrosion resistance.

\section{Acknowledgments}

This research is supported by the ASSAB STEELS TAIWAN CO., LTD. The authors would like to express their appreciations for Dr. Harvard Chen. 


\section{REFERENCE}

1) M. Niinomi: Metall. Mater. Trans., A Phys. Metall. Mater. Sci. 33 (2002) 477-486.

2) Y.L. Zhou and D.M. Luo: J. Alloy. Compd. 509 (2011) 6267-6272.

3) T. Duerig, A. Pelton and D. Stockel: Mater. Sci. Eng. A 273-275 (1999) 149-160.

4) P.J.S. Buenconsejo, K. Ito, H.Y. Kim and S. Miyazaki:Acta Mater. 56 (2008) 2063-2072.

5) H. Matsumoto, S. Watanabe and S. Hanada: J. Alloy. Compd. 439 (2007) 146-155.

6) W.D. Zhang, Y. Liu, H. Wu, M. Song, T.Y. Zhang, X.D. Lan and T.H. Yao: Mater. Charact. 106 (2015) 302-307.

7) S.H. Chang and P.Y. Chang: Mater. Sci. Eng. A 606 (2014) 150-156.

8) F.X. Xie, X.M. He, Y.M. Lv, M.P. Wu, X.B. He and X.H. Qu: Corros. Sci. 95 (2015) 117-124.

9) S.H. Chang, J.C. Chen, K.T. Huang and J.K. Chen: Mater. Trans. 54 (2013) 1034-1039.

10) S.H. Chang and S.L. Chen: J. Alloy. Compd. 585 (2014) 407-413.

11) M. Rahimian, N. Ehsani, N. Parvin and H.R. Baharvandi: J. Mater. Process. Technol. 209 (2009) 5387-5393.

12) S.H. Chang and P.Y. Chang: Mater. Sci. Eng. A 606 (2014) 150-156.
13) X.F. Zhao, M. Niinomi, M. Nakai and J. Hieda: Acta Biomater. 8 (2012) 1990-1997.

14) K. Otsuka and X. Ren: Prog. Mater. Sci. 50 (2005) 511-678.

15) P. Sun, Z.Z. Fang and M. Koopman: Adv. Eng. Mater. 15 (2012) 10071013.

16) S.H. Chang, Y.K. Lin and K.T. Huang: Surf. Coat. Tech. 207 (2012) 571-578.

17) B.B. Panigrahi: Mater. Lett. 61 (2007) 152-155.

18) H. Fujii: Nippon steel technical report, 62, (1994) 74-79.

19) C. Liang, S.H. Chang, J.R. Huang, K.T. Huang and S.T. Lin: Mater. Trans. 56 (2015) 1127-1132.

20) S.H. Chang and C.C. Chen: Mater. Trans. 55 (2014) 1755-1761.

21) N. Ergin and O. Ozdemir: ACTA Phys. Pol. A 123 (2013) 248-249.

22) E. Dudrová and M. Kabátová: Powder Metall. Prog. 8 (2008) 59-75.

23) Y.L. Zhou and D.M. Luo: Mater. Charact. 62 (2011) 931-937.

24) B.S. Sung, T.E. Park and Y.H. Yun: Adv. Mater. Sci. Eng. 2015 (2015) $1-7$.

25) F.R. Marciano, E.C. Almeida, D.A. Lima-Oliveira, E.J. Corat and V.J. Trava-Airoldi: Diamond Related Materials 19 (2010) 537-540.

26) R.L.O. Basso, R.J. Candal, C.A. Figueroa, D. Wisnivesky and F. Alvarez: Surf. Coat. Tech. 203 (2009) 1293-1297.

27) S.H. Chang, T.P. Tang and K.T. Huang: ISIJ Int. 50 (2010) 569-573. 